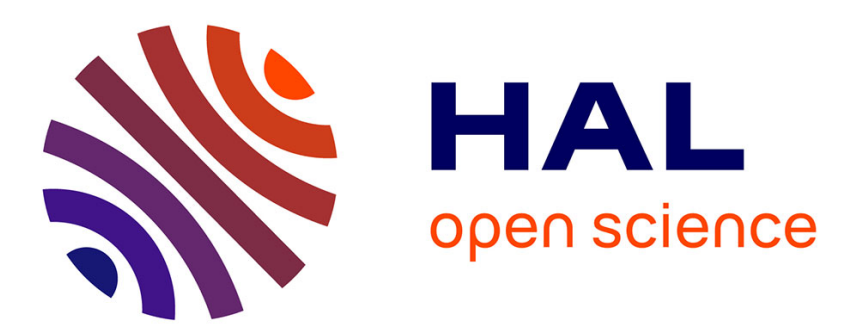

\title{
Improving VOC recuperative incinerators performances by increasing turbulence levels inside the combustion chamber -experimental results
}

Sylvain Salvador, Yilmaz Kara, M. Crussol

\section{- To cite this version:}

Sylvain Salvador, Yilmaz Kara, M. Crussol. Improving VOC recuperative incinerators performances by increasing turbulence levels inside the combustion chamber -experimental results. Applied Thermal Engineering, 2005, 25 (13), p. 1871-1881. 10.1016/j.applthermaleng.2005.03.006 . hal-01846929

\author{
HAL Id: hal-01846929 \\ https://hal.science/hal-01846929
}

Submitted on 6 Nov 2018

HAL is a multi-disciplinary open access archive for the deposit and dissemination of scientific research documents, whether they are published or not. The documents may come from teaching and research institutions in France or abroad, or from public or private research centers.
L'archive ouverte pluridisciplinaire HAL, est destinée au dépôt et à la diffusion de documents scientifiques de niveau recherche, publiés ou non, émanant des établissements d'enseignement et de recherche français ou étrangers, des laboratoires publics ou privés. 


\title{
Improving VOC recuperative incinerators performances by increasing turbulence levels inside the combustion chamber-experimental results
}

\author{
S. Salvador ${ }^{\mathrm{a}, *}$, Y. Kara $^{\mathrm{b}}, \mathrm{J}-\mathrm{M}$. Crussol $^{\mathrm{c}}$ \\ ${ }^{a}$ Ecole des Mines d'Albi-Carmaux, Centre Energétique-Environnement, Laboratoire de Génie des Procédés des \\ Solides Divisés, UMR CNRS 2392, Campus Jarlard, Route de Teillet, 81013 Albi CT Cedex 09, France \\ ${ }^{\mathrm{b}}$ Gaz de France Research and Development Division, Industrial Utilisation Section, 361 Avenue du Président \\ Wilson 93211 Saint-Denis La Plaine Cedex, France \\ ${ }^{\mathrm{c}}$ Sargi, 10, Cite' d'Angoule me, 75011 Paris, France
}

\begin{abstract}
Recuperative incinerators are used to eliminate volatile organic compounds (VOC) present in air fluxes prior to their release into the atmosphere. In this process, the air flow is heated to approximately 700 $800{ }^{\circ} \mathrm{C}$ and maintained at this temperature for roughly $0.5-1 \mathrm{~s}$. VOCs are cracked into light hydrocarbon species, and oxidised with the oxygen of the air flow into $\mathrm{CO}_{2}$ and $\mathrm{H}_{2} \mathrm{O}$. To reach this temperature, it is necessary to feed the incinerator with external Natural Gas (NG). With the goal of minimising the NG consumption of the process, the reaction temperature must be maintained at a value as low as possible. Under these conditions, the factor that limits the incinerator performance is $\mathrm{CO}$ emissions, that can rapidly exceed several tens of thousands of ppmv if the temperature is decreased; the upper limit regarding regulation is $100 \mathrm{mg} \mathrm{m}^{-3}$ at STP, or $80 \mathrm{ppmv}$. Turbulators with various geometry can be introduced inside the combustion chamber (CC) to enhance the $\mathrm{CO}$ oxidation to $\mathrm{CO}_{2}$ reaction, through an increase in the turbulence level of the flow. Nevertheless, no quantitative data about the impact of the technique on the combustion can be found in the literature.

In the present paper, experimental results are reported on the effect of inserting turbulators of different configuration inside the combustion chamber. Depending on the position of the turbulator, $\mathrm{CO}$ emissions
\end{abstract}

\footnotetext{
* Corresponding author. Tel.: +33 5634931 27/30 00; fax: +335634932 43/3099.

E-mail address: salvador@enstimac.fr (S. Salvador).
} 
can be drastically reduced. In the best case and in spite of the fact that the turbulator geometry is not yet optimised, CO emissions are reduced from $1990 \mathrm{ppmv}$ down to $600 \mathrm{ppmv}$. This is equivalent to a possible decrease in the exit temperature of $30^{\circ} \mathrm{C}$ keeping $\mathrm{CO}$ emissions at the same level in the case where the turbulator is used. This is also equivalent to a reduction of $5.4 \%$ in the NG consumption of the incinerator.

Keywords: VOC; Recuperative incinerators; Combustion; Turbulence; Emissions

\section{Introduction}

Very significant air flows containing volatile organic compounds (VOC) are generated in numerous industrial sectors across the world. On the planetary scale, natural sources of VOC and in particular vegetation and forest fires prevail: they account for $90 \%$ of the emissions. In industrialised areas, these emission sources become minor [1]. In France, 16\% of the VOC emissions are of natural origin while $84 \%$ are related to human activities [2]. With respectively $46 \%$ and $31 \%$ of the anthropic emissions, the transport and the use of organic solvents are the principal sources of VOC [2]. It is within the framework of the VOC elimination resulting from the industrial production that our work is aimed. Since VOC are harmful to animals and plants, and additionally contribute to the green house effect, it is necessary to treat these air streams in order to remove VOCs prior to their release into the atmosphere. One of the most commonly used techniques today is to oxidise them into $\mathrm{CO}_{2}$ and $\mathrm{H}_{2} \mathrm{O}$ using a recuperative incinerator $[3,4]$. The general principle of the process is schematised in Fig. 1. The air flux containing VOC is first preheated by crossing a gas-gas heat exchanger. It is then fed to a combustion chamber (CC). As shown in Fig. 2, this chamber is fitted at the inlet with an "in vein" burner supplied with Natural Gas (NG). Part of the air flow passes through perforated planes called "wings" and feeds the flame which is stabilised downstream of the burner. Two diaphragms are placed symmetrically above and below the burner wings, and leave two free sections (air veins), through which the main part of the air flux is blown. The diaphragm is employed [5]:

- to create air recirculation downstream, in order to obtain good mixing between the hot gases from the flame and the "cold" air flow that crosses the air veins,

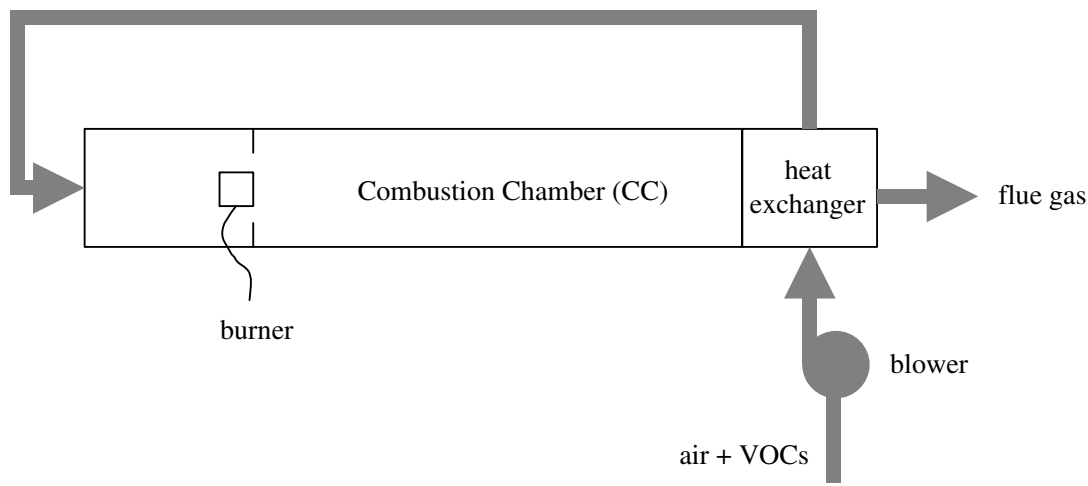

Fig. 1. Principle of a VOC recuperative incinerator. 


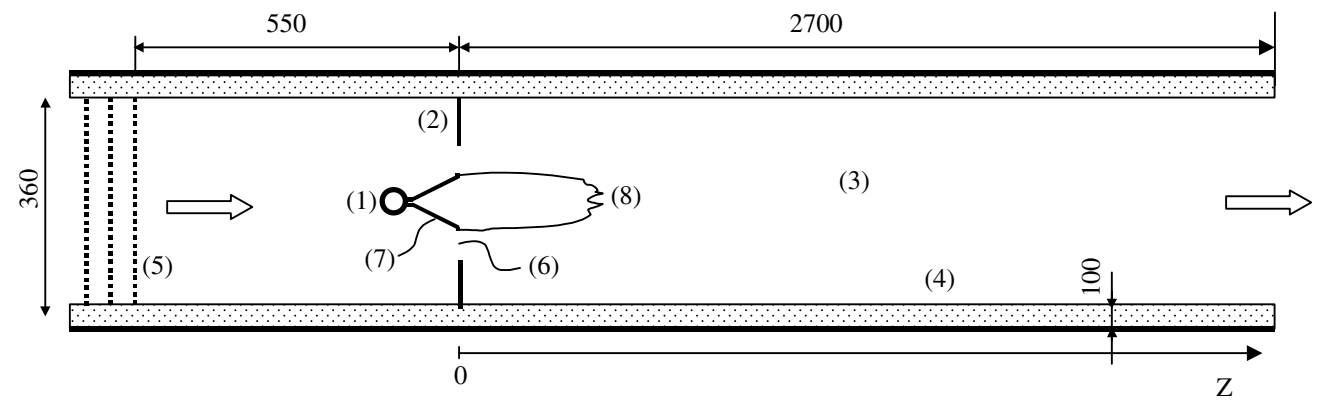

Fig. 2. General assembly of a VOC recuperative incinerator. (1) Burner; (2) diaphragms; (3) combustion chamber; (4) thermal insulation; (5) flow straightener; (6) air veins; (7) burner wings; (8) flame.

- to increase the turbulence levels inside the combustion chamber, in order to enhance the oxidation of the VOCs.

The aperture of the diaphragms can be adjusted. This will also affect the repartition of the air flow between the burner and the air veins, and consequently control the richness of the NG flame.

The temperature level inside such a reactor can be characterised by the output temperature of the $\mathrm{CC}$, where the temperature field is quite uniform on a cross section. This level is typically in the range of $700-800{ }^{\circ} \mathrm{C}$. This hot air stream crosses the heat exchanger, and is cooled down to typically $350-400{ }^{\circ} \mathrm{C}$ before being released to the atmosphere.

One of the advantages of this technology is that, by using large width burners and combining them into $\mathrm{H}$ or I shaped ramps, it is possible to build incinerators with very high treatment capacities [5].

The environmental performance of a VOC incinerator is evaluated through the following criteria:

- the destruction efficiency of VOCs. Depending on the VOC toxicity, efficiencies ranging between $95 \%$ and $99.999 \%$ can be aimed at $[6,7]$.

- $N O_{x}$ emissions. The flame generated by the burner also has the role to stabilise the combustion inside the CC. As a consequence, this flame has to be "hard", and its temperature is typically between $1950{ }^{\circ} \mathrm{C}$ and $2150^{\circ} \mathrm{C}$ : thermal $\mathrm{NO}_{x}$ are formed by the flame [5,8]. Todays regulation sets a limit at $100 \mathrm{mg} \mathrm{m}^{-3}$ at STP of equivalent $\mathrm{NO}_{2}$, or $50 \mathrm{ppmv} \mathrm{NO}_{x}\left(\mathrm{NO}+\mathrm{NO}_{2}\right)$ at the exit of the incinerator [9].

- $\mathrm{CO}$ emissions. The species $\mathrm{CO}$ is an intermediate species in the combustion of VOCs. The reaction mechanism to oxidise it into $\mathrm{CO}_{2}$ is quite slow. For low temperature operation, the concentration of $\mathrm{CO}$ at the exit of the incinerator can increase to more than several thousands ppmv [5].

In a previous work [6], we have shown that the last criterion, e.g. CO emissions, is the principal factor that does not allow one to reduce the temperature inside the $\mathrm{CC}$, and consequently does not allow one to reduce the NG consumption. In this paper, we show that increasing the turbulence level inside the $\mathrm{CC}$ accelerates the oxidation of $\mathrm{CO}$ into $\mathrm{CO}_{2}$. We first describe the incinerator used for the experiments, as well as the two turbulators that were developed and tested. Then 
we examine the impact of these turbulators on the combustion process, in terms of their position along the $\mathrm{CC}$.

\section{Experimental setup}

A prototype of an industrial recuperative incinerator at half scale was designed and built at Ecole des Mines d'Albi-Carmaux. A detailed description of the apparatus may be found in [5]. Experimental work on NO emissions reduction conducted on this apparatus has been described elsewhere [10]. A general view of the incinerator and surroundings is provided in Fig. 3. The cross section of the CC is $320 \mathrm{~mm}$ wide and $360 \mathrm{~mm}$ high. The $75 \mathrm{~kW}$ burner consists of a $300 \mathrm{~mm}$ large and $80 \mathrm{~mm}$ high ramp. Tests were carried out with a diaphragm height of $109 \mathrm{~mm}$, resulting in air veins height of $31 \mathrm{~mm}$. It was estimated, from numerical modelling [5], that approximately $18 \%$ of the air flow crosses the wings of the burner. The air flux velocity upstream of the burner was homogenised on a cross section using three perforated plates (Fig. 2, flow straightener). The length of the CC downstream of the burner is $2700 \mathrm{~mm}$. A refractory steel tube heat exchanger is used to recover part of the energy of the flue gas. A $25 \mathrm{~kW}$ electric heater is placed downstream to accurately set the air preheating temperature before entering the $\mathrm{CC}$. Liquid VOC, ethyl acetate in this case, is injected by spraying in compressed air downstream of the electric air heater. The air flow, the liquid VOC flow rate and the air preheating temperature were measured and controlled. Experiments were conducted several times so to ensure consistent results. For instance $\mathrm{NO}_{x}$ mea-

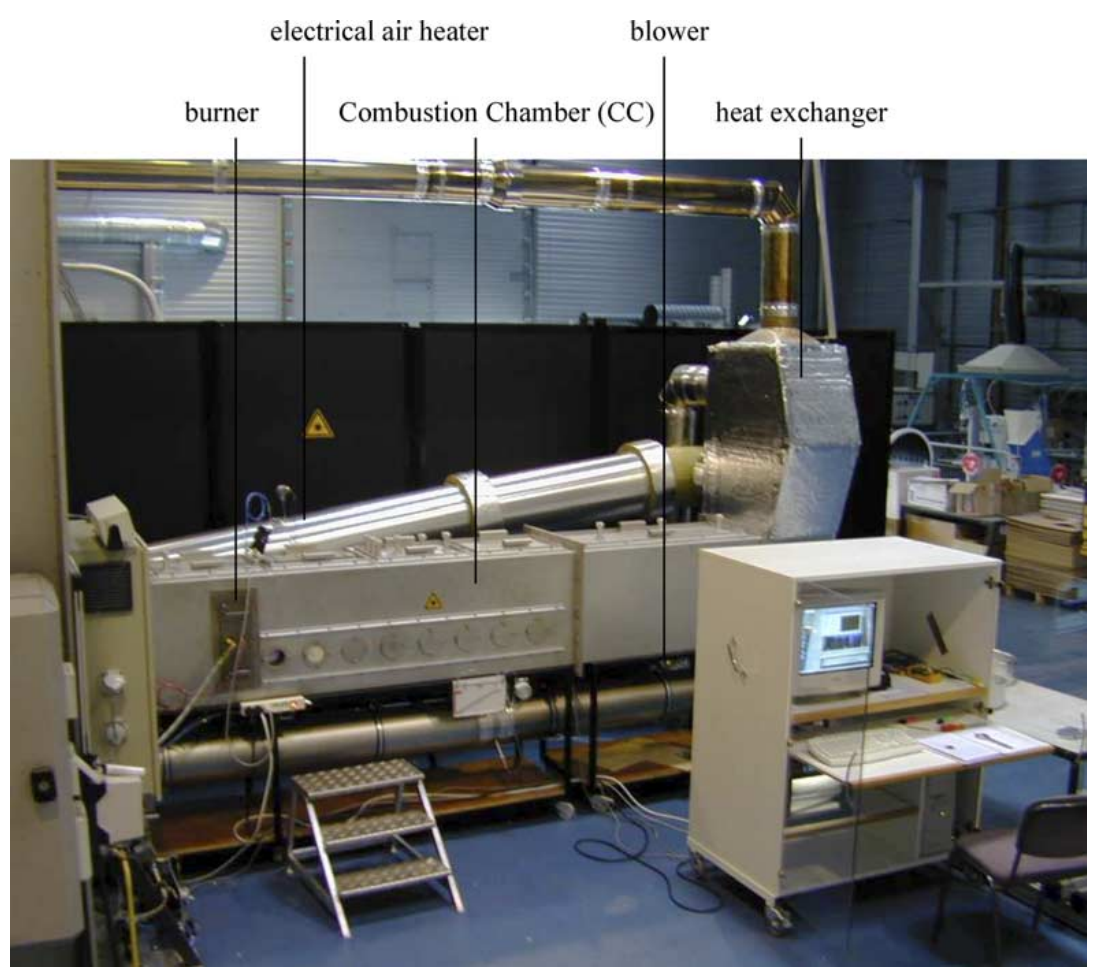

Fig. 3. General view of the recuperative incinerator and of its surroundings. 
surements or CO measurements, if repeated on different days, would lead to values of $20 \pm 2$ ppmv and $1990 \pm 50$ ppmv respectively.

The conditions for all the tests reported here are the following. The air flow rate was set to $468 \mathrm{~m}^{3} \mathrm{~s}^{-1}$ (at STP), and the VOC concentration was maintained at $9.1 \mathrm{~g} \mathrm{~m}^{-3}$ (at STP). The air preheating temperature was set to $376^{\circ} \mathrm{C}$ and the exit temperature was fixed at $715^{\circ} \mathrm{C}$.

The first turbulator is designed according to the following characteristics; its geometrical arrangement is illustrated in Fig. 4. The diameter of the tubes must be large enough so that the tubes do not bend under their weight; $17.1 \mathrm{~mm}$ o.d. refractory steel $(304 \mathrm{~L})$ tubes are used. Since the average velocity for the hot air is approximately $4.5 \mathrm{~m} . \mathrm{s}^{-1}$, the Reynolds number for each tube is 3100. For this flow regime, i.e. for Reynolds numbers ranging from 60 to 5000, vortices are formed downstream of each tube and are blown downstream. It is expected that this regime will promote turbulence in an important volume downstream of each tube.

We have adopted here, as a single assembly module of tubes, 2 vertical staggered rows of 6 tubes each. The staggered assembly is known as a classical way to maximise the exchange between a fluid and the external surface of a "bank" of tubes, while minimising the pressure drop in the fluid phase. This is why this configuration was adopted here. The 12 tubes have a projected surface of $65664 \mathrm{~mm}^{2}$, which represents an obstructed surface of $57 \%$ of the section of the CC.

From the results of a numerical model developed in a previous work [5], it is thought that the region where the oxidation of $\mathrm{CO}$ is limited by micro-mixing efficiency is located around an

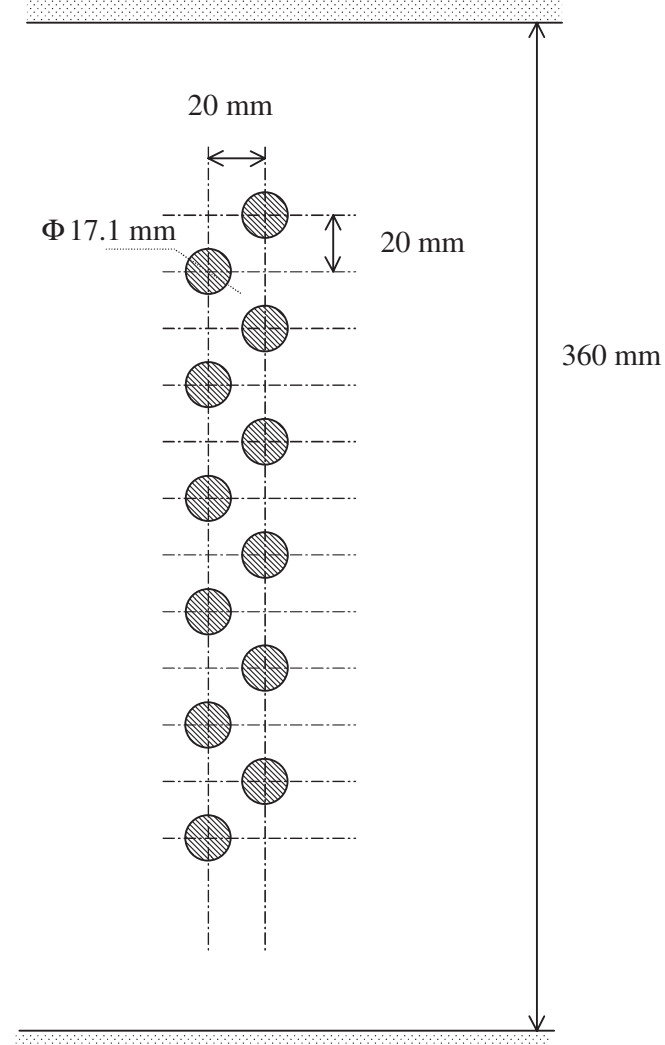

Fig. 4. Arrangement of the tubes in a single turbulator module. 
horizontal plane at half the height of the $\mathrm{CC}$. This is why no tubes were placed close to the upper and bottom walls of the CC.

In an industrial application, a number of these assembly can be placed inside the CC. In this paper, the case of one assembly and the case of two assemblies have been examined.

\section{Results}

Flue gases at the exit of the CC are sampled using a water cooled probe. They are analysed in real time for $\mathrm{O}_{2}$ using a paramagnetic analyser (SERVOMEX), for $\mathrm{CO}$ and $\mathrm{NO}_{x}$ using non-dispersive Infra Red analysers (SERVOMEX), and for total hydrocarbons (unburned hydrocarbons) using a Flame Ionisation Detector (COSMA S.a. Environnement). The oxygen content of the flue gases was found to be $17.4 \%$.

The turbulator was placed closed to the burner, at $500 \mathrm{~mm}$, and fitted with a steel wire that crosses the end wall of the CC. The incinerator was started and the steady state was reached after $5 \mathrm{~h}$. The turbulator was then moved step by step by pulling on the wire from the outside and measurements were taken once the steady state regime was re-established.

We report in Fig. 5 the evolution of $\mathrm{CO}$ concentration at the exit of the $\mathrm{CC}$ versus the position of the turbulator. The CO emissions without the turbulator were recorded at $1990 \mathrm{ppm}$. This value is recovered when the turbulator is placed close to the CC exit, where it has no more impact. It is clear from this figure that the turbulator can enhance the oxidation of $\mathrm{CO}$ into $\mathrm{CO}_{2}$. The impact is maximum when the turbulator is placed $500 \mathrm{~mm}$ downstream the burner. The effect decreases when the turbulator is moved further from the burner, as indicated by the increase in $\mathrm{CO}$ emissions. Positions closer to the burner were not tested because we have estimated that, regarding the high temperatures reached inside the flame zone, the life time of the turbulator, both during our tests and in future industrial applications, would be severely shortened. These results indicate that there is a large zone of the $\mathrm{CC}$ where the reaction rate for the oxidation of $\mathrm{CO}$ into $\mathrm{CO}_{2}$ depends on the turbulence intensity.

It is clear today that a gas phase reaction such as the ones involved in this combustion process can be controlled by two types of mechanism:

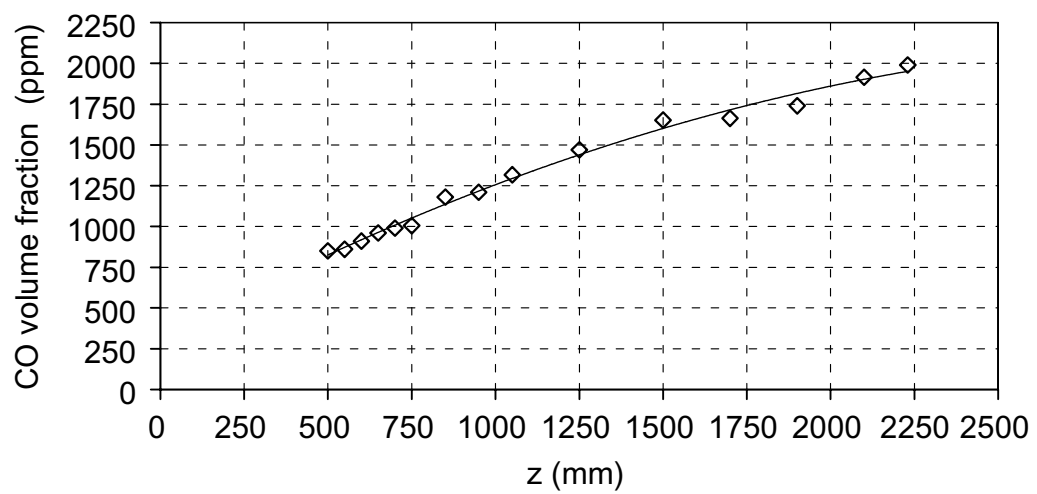

Fig. 5. Evolution of the $\mathrm{CO}$ volume fraction at the exit of the combustion chamber versus the position of the one module turbulator. 
(i) In the case where reactants and products are perfectly mixed and where the temperature is homogeneous, the reaction rate is determined by the kinetics of the chemical reaction. Today's numerical models describe this through the calculation of an Arrhenius reaction rate. The main factors affecting the reaction rate are the local temperature and the species concentrations.

(ii) In the case where the reaction kinetics is rapid, the reaction rate is controlled by the micromixing of the reactant and of the product species. Magnussen et al. [11] proposed a simple theory to calculate this reaction rate. They show that this mechanism can control the combustion in numerous applications, including the case of premixed combustion. In this situation, the main factors affecting the reaction rate are the kinetic energy $k$ and its dissipation rate $\varepsilon$. Following the concept of Spalding et al. [12], the term $k / \varepsilon$ represents a characteristic time for the turbulent structures; the reverse of this term is the local micro-mixing efficiency.

The dependence of the reaction rate of the $\mathrm{CO}$ oxidation reaction observed here indicates that in almost all the $\mathrm{CC}$ the reaction is controlled by micro-mixing; indeed increasing the turbulence level accelerates the reaction. The micro-mixing considered here should not be confused with mixing at the scale of the reactor. The tubes here do not homogenise the temperature and species concentrations at the scale of the $\mathrm{CC}$, but introduce turbulence that will enhance mixing of fresh gases and burned gases at a scale closed to molecular scale. In such a situation of micro-mixing controlled reaction, an important increase in the temperature is required for a small increase in the reaction rate.

It is difficult at this stage to evaluate the volume of the reactor downstream of the turbulators that is affected by them. One could imagine from the previous results that the turbulator, placed $500 \mathrm{~mm}$ downstream of the burner, generates turbulence along the length of the $\mathrm{CC}$ and enhances $\mathrm{CO}$ oxidation, and that moving it downstream reduces the volume where turbulence levels are increased. This would explain the decrease in CO concentration. Moreover, it is not possible to establish from these results if another increase in the turbulence level could further increase the $\mathrm{CO}$ oxidation efficiency. In order to bring some understanding, tests were conducted with 2 modules such as the one used before, placed side by side. The results obtained in terms of $\mathrm{CO}$ emissions as a function of the position of the turbulator along the $\mathrm{CC}$ are given in Fig. 6.

Overall, it is clear that doubling the number of tubes increases the $\mathrm{CO}$ oxidation efficiency. Therefore the reaction is still controlled by micro-mixing in the case of the single module turbulator.

Let us now consider the evolution of $\mathrm{CO}$ emissions as a function of the position of the turbulator. When the turbulator is placed closed to the burner, it has an important impact. The CO emissions remain almost constant as the turbulator is moved up to $1 \mathrm{~m}$. Beyond $1 \mathrm{~m}$, CO emissions increase; naturally, at the end of the CC, the turbulator becomes useless, and the $1990 \mathrm{ppmv}$ $\mathrm{CO}$ concentration is recovered. The improvement in $\mathrm{CO}$ oxidation by the one module turbulator and by the two modules turbulator appear not to remain proportional as the turbulators are moved along the chamber. It is not possible to give explanations in terms of physical phenomena, regarding the non linearity of the thermal, fluid mechanics and chemical phenomena involved here. It is still difficult from these results to determine the volume of the CC downstream of 


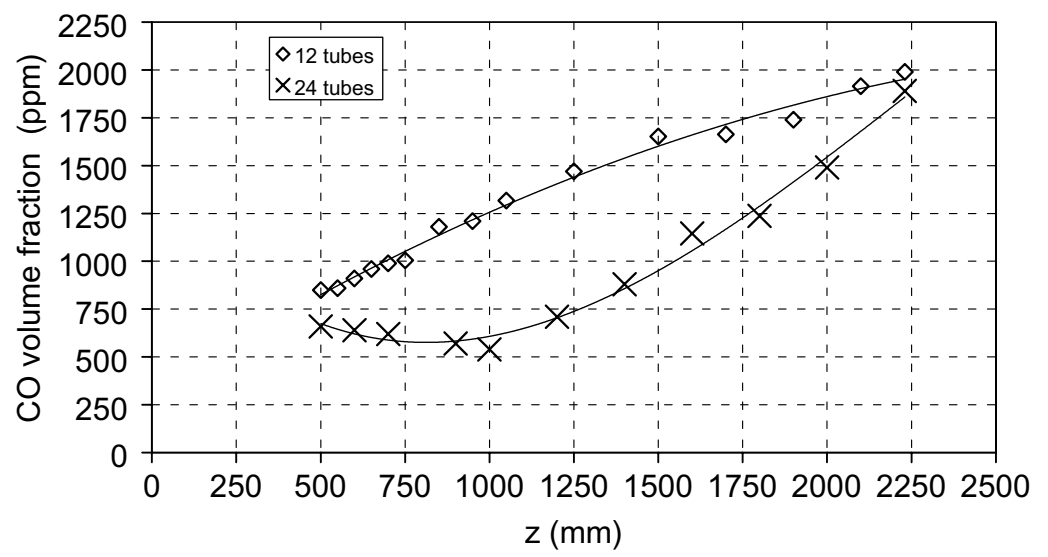

Fig. 6. Evolution of the $\mathrm{CO}$ volume fraction at the exit of the combustion chamber versus the position of $(\diamond)$ the one module turbulator and of $(\mathrm{X})$ the two modules turbulator.

the turbulator in which turbulence is significantly intensified. We can only say from these results that it does not cover the whole length of the $\mathrm{CC}$, otherwise the efficiency would always decrease when the turbulator is moved from the burner to the exit of the CC.

As far as the pressure drop introduced by the turbulators is concerned, it was measured with two static pressure tappings placed at the walls upstream of the burner and at the exit of the CC. The pressure drop was about $20 \mathrm{~Pa}$ for the two modules turbulator. This can be compared, for reference, with the total pressure drop of the incinerator that is circa $640 \mathrm{~Pa}$.

If one focuses on the VOCs destruction efficiency, we can refer to the Total Hydrocarbons emissions. For all the experiments performed in this work, their concentration remained smaller than $10 \mathrm{ppm}$, whether the turbulators were used or not. It can be thought that turbulators have increased the kinetics of the chemical reactions that crack the VOCs into lighter hydrocarbons and the reaction to oxidise the $\mathrm{HC}$ into $\mathrm{CO}, \mathrm{CO}_{2}$ and $\mathrm{H}_{2} \mathrm{O}$.

As far as NO emissions are concerned, one debate whether if the turbulators enhance their formation or not. The emissions were recorded during all experiments. As indicated by the plots in Fig. 7, the $\mathrm{NO}_{x}$ emissions were similar for all the experiments. This is probably due to the fact that the turbulators were always placed downstream of the flame. $\mathrm{NO}_{x}$ are known to form inside the flame [5]: the turbulators did not have any impact on their formation.

The question of designing the best turbulator for an industrial incinerator is beyond the scope of this paper. It can nevertheless be discussed here. In this context, the criteria to evaluate the global improvement of the incinerator through the addition of a turbulator are:

- the reduction in $\mathrm{CO}$ emissions, resulting in a possible decrease in the operating temperature and consequently in a decrease in NG consumption, at constant $\mathrm{CO}$ emissions.

- the cost of using a turbulator, that stems from:

- buying the refractory materials;

- installing the turbulator;

- eventual maintenance;

- additional cost for air blowing due to the increase of the incinerator pressure drop. 


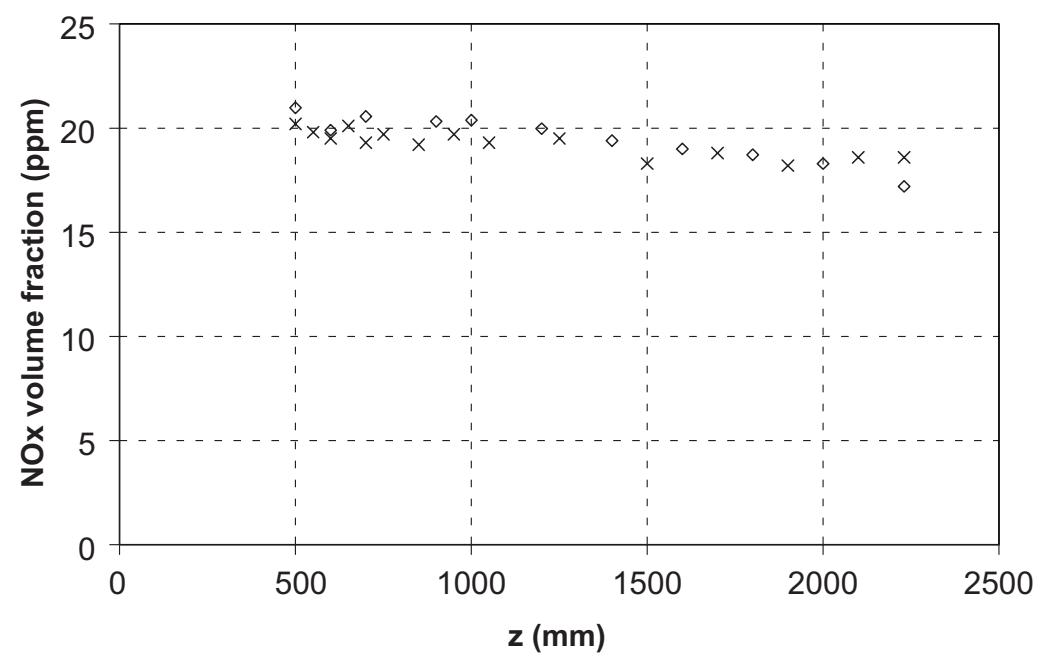

Fig. 7. Evolution of the $\mathrm{NO}_{x}$ volume fraction at the exit of the combustion chamber versus the position of $(\diamond)$ the one module turbulator and of $(\mathrm{X})$ the two modules turbulator.

As far as the last point is concerned, the present results indicate that the pressure drop should not be the limiting criterion for turbulators amounting to several modules of 12 tubes each.

The present results also indicate that, in order to limit the investment cost for the refractory materials together with the maintenance cost, the turbulator should be placed far from the burner, but not further than $1 \mathrm{~m}$. Should one consider the efficiency of more than 2 turbulator modules, additional tests are required. More generally, the tubes diameter, their spacing and the distance between each row should also be varied and optimised. Nevertheless, the large number of parameters entering in the design of the turbulator lead to a very large number of possible configurations, that could not be tested in the frame of this work.

Should numerical modelling be envisioned as a way to optimise the geometry of a turbulator, the difficulty will be to describe accurately the impact on the turbulence levels of the tubes. In the regime where vortices are periodically detached from each tube, and in the case of a complex geometry such as that of the incinerator, the CPU time cost will be very high.

\section{Conclusions}

When VOC recuperative incinerators are operated at moderate temperatures for reducing their natural gas consumption, the limitation encountered is not unburned VOC emissions but $\mathrm{CO}$ emissions.

It was shown that the introduction of a two row 12 tubes $17.1 \mathrm{~mm}$ turbulator inside the combustion chamber decreases the $\mathrm{CO}$ emissions from $1990 \mathrm{ppmv}$ down to $780 \mathrm{ppm}$. The highest efficiency was obtained when the turbulator is placed $500 \mathrm{~mm}$ downstream to the burner.

Using two modules further decreases $\mathrm{CO}$ emissions down to 600 ppmv approximately. This variation in $\mathrm{CO}$ emissions is equivalent to a change in the $\mathrm{CC}$ temperature of $30^{\circ} \mathrm{C}$. This is equivalent to saving $5.4 \%$ of the NG supply. 
The ratio of the $\mathrm{CO}$ reduction efficiency of the two modules turbulator to that of the single module turbulator does not remain constant when the turbulator is moved along the CC. It was not possible to explain this at this stage. For a longer lifetime, a 24 tube turbulator should be placed far from the burner, but not further than $1 \mathrm{~m}$ from the burner for a good efficiency.

It is thought that the $\mathrm{CO}$ oxidation efficiency enhancement by turbulence level increase is due to an increase in the micro-mixing efficiency, that enables the chemical reaction acceleration through a better mixing, at a very small scale, of the burned gases with the fresh gases. The results presented here reveal that the incinerator performance is limited by micro-mixing if a turbulator is not used.

For all the configurations examined here, whether a turbulator is used or not, the emissions of hydrocarbons remained lower than $10 \mathrm{ppmv}$; it is likely that the use of a turbulator increases the VOC destruction efficiency.

$\mathrm{NO}_{x}$ emissions are not affected by the presence of a turbulator. They remain constant approximately at 20 ppmv no matter what the design and location of the turbulator.

It is beyond the scope of this paper to determine an optimal geometry for the turbulator, regarding the large number of parameters entering in the design: diameter of the tubes, distance between two tubes in a row, distance between the rows, number of rows to take only the most common parameters. These results bring us to think that additional rows could still increase the $\mathrm{CO}$ oxidation efficiency. The pressure drop introduced by two modules is small: $20 \mathrm{~Pa}$. Pressure drops should not be a limit in considering the addition of more than two tube rows.

Since the design of the turbulator proposed here is very simple, and the quantities of refractory materials required to build them are very small, this technique shows promise for industrial applications. It reduces the cost of VOC incineration through the decrease in NG consumption, and consequently limits the environmental impact of the process through $\mathrm{CO}_{2}$ emissions reduction. $\mathrm{NO}_{x}$ emissions are not affected, and VOC destruction efficiency is certainly enhanced.

\section{References}

[1] P. Dégé, Elimination de composés organiques volatils (COV)—Oxydation catalytique de l'O-Xylène sur catalyseurs palladium et platine/Zéolithes, Thèse de Doctorat (PhD) de l'Universitéde Poitiers, France, 1999.

[2] N. Dueso, La réduction des émissions de composés organiques volatils dans l'industrie, Editions Ademe Angers, France, 1997.

[3] E.N. Ruddy, L.A. Caroll, Select the best VOC control strategy, Chemical Engineering Progress 89 (7) (1993) $28-$ 35.

[4] D.R. Van Der Vaart, E.G. Marchand, A. Bagely-Pride, Thermal and catalytic incinerators for the controls of volatile organic compounds, Journal of Air and Waste Management Association 41 (1) (1991) 92-98.

[5] Y. Kara, Oxydation thermique des Composés Organiques Volatils (COV) en épurateur récupératif-Optimisation des outils de dimensionnement, Thèse de Doctorat (PhD) de l'INP Toulouse, France, 2003.

[6] L. Bussac, E. Caverne, Veille technologique sur le traitement des COV, CERUG/GDF 962696, 1996.

[7] B. Mortgat, Traitement des COV-Les procédés d'incinération pour anticiper sur le futur bilan solvant, Environment \& Technique 168 (1997) 23-27.

[8] D.M. Stansel, N.M. Laurendeau, D.W. Senser, $\mathrm{CO}$ and $\mathrm{NO}_{x}$ emissions from controlled-air burner: Experimental measurements and exhaust correlations, Combustion Science and Technology 104 (4-6) (1995) 207-234.

[9] Arrêté relatif aux prélèvements et à la consommation d'eau ainsi qu'aux émissions de toute nature des installations classées pour la protection de l'environnement soumises à autorisation, Ministère de l'aménagement du territoire et de l'environnement, Journal Officiel de la République Française, arrêté du 2 février 1998, modifié le 29 mai 2000. 
[10] S. Salvador, Y. Kara, J.-M. Commandré, Reduction of NO emissions from a VOC recuperative incinerator by dilution of the fuel supply, Applied Thermal Engineering 24 (2004) 245-254.

[11] B.F. Magnussen, B.H. Hjertager, On mathematical models of turbulent combustion with special emphasis on soot formation and combustion, in: 16th International Symposium on Combustion, The Combustion Institute, 1976.

[12] D.B. Spalding, Mixing chemical reaction in steady confined turbulent flames, in: 13th International Symposium on Combustion, The Combustion Institute, 1970. 